\title{
Overuse and Misuse of Inhaled Corticosteroids Among Veterans with COPD: a Cross-sectional Study Evaluating Targets for De-implementation
}

\author{
Matthew F. Griffith, $M D, M P H^{1,2,3}$, Laura C. Feemster, $M D, M S^{2,3}$, \\ Steven B. Zeliadt, PhD, MPH' , Lucas M. Donovan, MD, MS $S^{2,3}$, Laura J. Spece, MD, MS $S^{2,3}$, \\ Edmunds M. Udris, $\mathrm{MPH}^{2}$, and David H. Au, MD, MS $\mathrm{S}^{2,3}$
}

\begin{abstract}
'Seattle-Denver Center of Innovation for Veteran-Centered \& Value-Driven Care, VA Eastern Colorado Health Care System, Aurora, CO, USA; ${ }^{2}$ Seattle-Denver Center of Innovation for Veteran-Centered \& Value-Driven Care, VA Puget Sound Health Care System, Seattle, WA, USA; ${ }^{3}$ Division of Pulmonary, Critical Care and Sleep Medicine, University of Washington, Seattle, WA, USA.
\end{abstract}

BACKGROUND: Inhaled corticosteroid (ICS) use among patients with COPD increases the risk of pneumonia and other complications. Current recommendations limit ICS use to patients with frequent or severe COPD exacerbations. However, use of ICS among patients with COPD is common and may be occurring both among those with mild disease (overuse) and those misdiagnosed with COPD (misuse).

OBJECTIVE: To identify patients without identifiable indication for ICS and assess patient and provider characteristics associated with potentially inappropriate to targeted in de-implementation efforts

DESIGN: We performed a cross-sectional study of patients with COPD in the Veterans Affairs (VA) system with recent spirometry.

PARTICIPANTS: After setting an index date, we identified individuals with a clinical diagnosis of COPD who had spirometry completed in the prior 5 years. We excluded individuals with an appropriate indication for ICS based on the 2017 GOLD statement, including asthma and a recent history of frequent or severe exacerbations.

MAIN MEASURES: ICS use without identifiable indication

KEY RESULTS: We identified 26,536 patients with COPD without an identifiable indication for ICS. Nearly $1 / 4$ of patients ( $n=6330$ ) filled $\geq 2$ prescriptions for ICS in the year prior to the index date. We found that older age (adjusted prevalence ratio [APR] 1.06 per decade, 95\% confidence interval [CI] 1.04-1.08), white race (APR 1.11, 95\% CI 1.05-1.19), and more primary care visits (APR 1.05 per visit, 95\% CI 1.03-1.07) were associated with increased likelihood of potentially inappropriate use. Primary care clinic complexity and provider training were not associated with ICS use. Among patients misdiagnosed with COPD, we found that 14\% used ICS.

CONCLUSIONS: Potentially inappropriate ICS use is common among patients with and without airflow obstruction who are diagnosed with COPD. We identified patient comorbidities and patterns of healthcare utilization that

Prior Presentation Portions of this work were presented at the American Thoracic Society meeting in Dallas, TX, USA in May 2019.

Received March 26, 2019

Revised August 20, 2019

Accepted September 12, 2019

Published online November 11, 2019 increase the likelihood of ICS use that could be targeted for system-level de-implementation interventions.

KEY WORDS: overuse; misuse; de-implementation; de-prescribing; COPD care quality.

J Gen Intern Med 35(3):679-86

DOI: $10.1007 / \mathrm{s} 11606-019-05461-1$

(c) Society of General Internal Medicine (This is a U.S. government work and not under copyright protection in the U.S.; foreign copyright protection may apply) 2019

\section{INTRODUCTION}

Long-acting inhaled medications reduce the severity of symptoms and exacerbation risk among patients with COPD..$^{1-8}$ Numerous observational studies and clinical trials have demonstrated that use of inhaled corticosteroids (ICS) increases the risk of pneumonia, leading professional organizations and providers to reconsider the safety of these medications. ${ }^{1,9-12}$ In 2011, the Global Initiative for Obstructive Lung Disease (GOLD) committee limited the recommended use of ICS to individuals classified as having frequent exacerbations or severe airflow obstruction (AFO). ${ }^{13}$ An updated statement in 2017 further narrowed appropriate indications to only those individuals experiencing frequent or severe exacerbations. ${ }^{14}$

Despite these narrow indications, ICS remain among the most commonly prescribed inhaled medications in the treatment of COPD ${ }^{12,}{ }^{15-17}$ Bringing care into alignment with current evidence and the most recent GOLD recommendations represents an opportunity to improve safety of care through de-implementation of a low-value practice, as the risk of pneumonia falls quickly after discontinuation of ICS. ${ }^{12,}$ 15, 18 To develop effective and efficient de-implementation strategies, health systems need to understand the magnitude of potentially inappropriate ICS use as well as identify individual and health system factors that might contribute to the problem.

To this end, from the perspective of a health system seeking to align ICS use with current recommendations, we assessed the prevalence of ICS receipt among patients with a clinical diagnosis of COPD and no apparent indication based on the 
most recent GOLD statement. We also identified patient and primary care clinic characteristics associated with risk of potentially inappropriate ICS prescriptions.

\section{METHODS}

\section{Data Sources}

We obtained data from the Veterans Health Administration (VHA) corporate data warehouse (CDW). To define a cohort of patients that could be assessed for appropriateness of ICS, we limited our population to those with recent spirometry results available in the CDW. Our search of available spirometry data identified $16 \mathrm{VA}$ medical centers that provided this information to the CDW during our study period (20112016). Our study included patients receiving care at these medical centers and their associated primary care clinics.

\section{Design and Population}

We sought to define a cohort of patients who did not have an indication for an inhaled corticosteroid based on the most recent GOLD statement. ${ }^{14}$ As a health system might approach the issue to reduce potentially inappropriate ICS use, we set an index date (September 16, 2016) to identify a cohort of patients eligible for ICS de-implementation. We identified patients alive at the index date who were assigned a VA primary care provider and had an outpatient encounter for COPD within the past 2 years. We defined outpatient encounters for COPD using ICD-9/10 codes (ICD-9: 491.x, 492.x, or 496.x; ICD-10: J41-44.x). We used the 2017 GOLD statement to exclude patients with an appropriate indication for an inhaled corticosteroid. Appropriate indications included the following: (1) any diagnosis of asthma (ICD-9: 493.x, ICD-10: J45.x), (2) severe exacerbation defined as inpatient treatment for a COPD exacerbation in the year prior to the index date, and/or (3) frequent exacerbations, defined as 2 or more outpatient COPD exacerbations during the year prior to the index date. We defined an inpatient exacerbation of COPD as a hospitalization with a primary discharge diagnosis of COPD or a primary discharge diagnosis of respiratory failure (ICD-9: 518.81 or 518.84; ICD-10: J96.0, J96.2, or J96.9) and COPD as a secondary diagnosis. We defined an outpatient exacerbation as an outpatient COPD encounter with either a dispensation of an oral glucocorticoid or a respiratory antibiotic within 2 days of the encounter. We excluded patients from sites contributing fewer than 25 patients as these sites would likely be too small to provide a stable estimate of prevalence. ${ }^{19}$

\section{Primary Outcome}

Our primary outcome was potentially inappropriate inhaled corticosteroid prescription, defined as patients with an active prescription for an ICS on the index date who received at least two dispensations of an ICS in the prior year. Within VA, prescriptions are most often provided in 90-day dispensations.
Therefore, our outcome most likely reflected the receipt of at least a 6-month supply of ICS during the year prior to the index date.

\section{Secondary Outcomes}

We defined airflow obstruction as having a post-bronchodilator FEV1/FVC ratio of less than $0.7 .^{20}$ Because the approach to deescalation may be different for different groups of patients with a clinical diagnosis of COPD, we further categorized potentially inappropriate prescriptions of ICS as either "potential overuse" or "potential misuse." 21 We defined "potential overuse" as receipt of ICS by patients with airflow obstruction on spirometry and without a frequent or severe COPD exacerbation history. We defined "potential misuse" as receipt of ICS by patients who had no airflow obstruction by spirometry, refuting their clinical diagnosis of COPD.

\section{Predictors}

We assessed patient and primary care characteristics that we hypothesized would be associated with receipt of ICS. We included variables indicating higher healthcare utilization or increased symptoms of dyspnea, cough, or exercise intolerance that might be incorrectly attributed to COPD (e.g., obesity, cardiac disease, and depression). ${ }^{17,} 22,23$ We identified specific comorbidities in the electronic health record using groupings of ICD9/10 codes defined by Elixhauser et al. ${ }^{24}$ We assessed the number of primary care visits attended by the patient and number of hospitalizations in the VA system during the study period. To assess the association between primary care access and overuse of ICS, we used a 20-mile cutoff to identify patients at risk of decreased primary care access due to geographic inaccessability. ${ }^{25}$ We categorized primary care location by type of clinic (community-based vs. medical center) and provider type as MD or advanced practice provider (e.g., PA and NP).

\section{Analytic Approach}

We constructed a mixed effects Poisson model with robust standard error measurements to evaluate the association between inappropriate ICS and patient, provider, and clinic characteristics. ${ }^{26}$ We treated patient, provider, and clinic characteristics as covariates and treated primary care clinic as a random effect. We treated clinic as a random effect in our model in order to account for potential clustering of ICS prescribing behavior at the clinic level. ${ }^{27}$ We evaluated each patient, provider, and clinic characteristic independently in the unadjusted mixed effects Poisson model as well as adjusting for all factors in a multivariable model. We performed subgroup analyses for our secondary outcomes, restricted to patients with and without airflow obstruction, using the same model as the primary analysis to evaluate potential overuse and potential misuse. ${ }^{28}$ We used STATA Statistical Software (College Station, TX) version 15.1 for all analyses. 


\section{Sensitivity Analysis}

We sought to identify patients appropriate for deimplementation based on the most recent GOLD statements; however, statements in use during the study period also included severe airflow obstruction (defined as FEV1 $<50 \%$ predicted) as an additional possible indication for ICS. ${ }^{13}$ To determine if our findings would differ in a population defined using the older GOLD criteria, we performed a sensitivity analysis excluding those with severe airflow obstruction.

The activities summarized in this manuscript were conducted as part of a non-research evaluation approved under the authority of the VA Office of Specialty Care.

\section{RESULTS}

\section{Population}

We identified 38,848 patients with available spirometry results who met our inclusion criteria. Of these individuals, we excluded 10,553 patients who had an indication for ICS use based on the 2017 GOLD statement (Fig. 1). ${ }^{14}$ Among the remaining patients, we excluded 1759 from primary care clinics contributing fewer than 25 patients (Fig. 1). We included the remaining 26,536 individuals without an apparent indication for ICS in our analysis. Patients were seen in 113 primary care clinics, with each clinic contributing an average of 235 (SD 287) patients.]->

\section{Patient Characteristics}

The cohort was predominantly white $(82.2 \%)$ men $(96.9 \%)$, with an average age of 68.8 years (SD 9.3) (Table 1). Most patients received primary care in community-based outpatient clinics $(60.7 \%)$ from physician providers $(80.2 \%)$.

\section{Outcome}

We identified $6330(23.9 \%)$ patients with a clinical diagnosis of COPD who received ICS without an identifiable indication. Characteristics of the cohorts receiving ICS and not receiving ICS are reported in Table 1.

\section{Clinic Variation}

Prevalence of potentially inappropriate ICS prescriptions at primary care clinics ranged from 8 to $50 \%$, with a median of $24 \%$ (Fig. 2). We found considerable variation in potentially inappropriate ICS use across primary care clinics (IQR 21.028.5\%) (Fig. 2).] $\rightarrow$

\section{Likelihood of ICS Use}

The likelihood of potentially inappropriate ICS prescriptions increased with age (adjusted prevalence ratio [APR] 1.11 for every 10-year increase in age, 95\% confidence interval [CI] 1.04-1.08), identifying as "white" race (APR 1.11, 95\% CI 1.05-1.19), and with living greater than 20 miles from a patient's primary care clinic (APR 1.06, 95\% CI 1.00-1.11) (Table 2). Comorbid cardiac arrhythmias decreased the likelihood (APR 0.92, 95\% CI 0.87-0.97) while comorbid obesity, depression, and other cardiac conditions were not associated with potentially inappropriate ICS. The number of primary care appointments in the past year (APR 1.05, 95\% CI 1.031.07) but not the number of non-COPD hospitalizations was associated with potentially inappropriate ICS prescriptions. Primary care provider type (physician vs. APP) and clinic

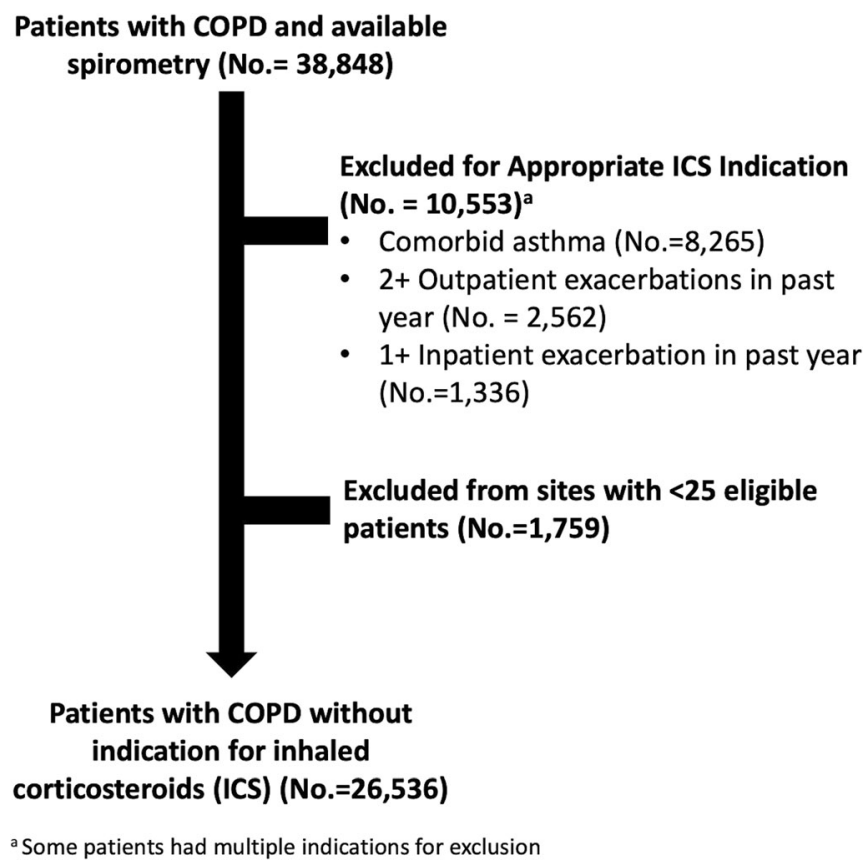

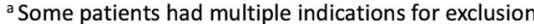

Figure 1 Flow diagram for identifying patients with COPD without indication for inhaled corticosteroid (ICS), from sites contributing at least 25 patients to the cohort. 
Table 1 Characteristics of Patients Diagnosed with COPD Without Indication for Inhaled Corticosteroid (ICS), by Receipt of ICS. Indications for ICS Included Frequent or Severe COPD Exacerbations and a History of Asthma

\begin{tabular}{|c|c|c|c|}
\hline & $\begin{array}{l}\text { Not receiving ICS } \\
\text { No. }=\mathbf{2 0 , 2 0 6}\end{array}$ & $\begin{array}{l}\text { Receiving ICS } \\
\text { No. }=6330\end{array}$ & $\begin{array}{l}\text { Total } \\
\text { No. }=26,536\end{array}$ \\
\hline \multicolumn{4}{|l|}{ Patient characteristics } \\
\hline Male, No. $(\%)$ & $19,539(96.7)$ & $6169(97.5)$ & $25,708(96.9)$ \\
\hline Age, mean (SD), years & $68.6(9.6)$ & $69.2(8.3)$ & $68.8(9.3)$ \\
\hline \multicolumn{4}{|l|}{ Race, No. (\%) } \\
\hline White & $16,512(81.7)$ & $5312(83.9)$ & $21,824(82.2)$ \\
\hline African-American & $2374(11.7)$ & $659(10.4)$ & $3033(11.4)$ \\
\hline Asian & $111(0.6)$ & $16(0.3)$ & $127(0.5)$ \\
\hline Native American & $170(0.8)$ & $53(0.8)$ & $223(0.8)$ \\
\hline Hawaiian/Pacific Islander & $192(1.0)$ & $52(0.8)$ & $244(0.9)$ \\
\hline Other/unknown & $847(4.2)$ & $238(3.8)$ & $1085(4.1)$ \\
\hline Airflow obstruction on spirometry, No. (\%) & $11,760(58.2)$ & $4922(77.8)$ & $16,682(62.9)$ \\
\hline PCPa appointments in last year, mean (SD) & $2.2(1.6)$ & $2.3(1.6)$ & $2.2(1.6)$ \\
\hline Non-COPD-related hospitalizations in last year, mean (SD) & $0.34(1.0)$ & $0.30(1.0)$ & $0.33(1.0)$ \\
\hline Living $>20$ miles from PCP, No. $(\%)$ & $5771(28.6)$ & $1940(30.6)$ & $7711(29.1)$ \\
\hline Elixhauser Comorbidity Score, mean (SD) & $3.7(2.5)$ & $3.8(2.3)$ & $3.8(2.4)$ \\
\hline \multicolumn{4}{|l|}{ Other inhaled medications, No. $(\%)$} \\
\hline Albuterol & 9459 (23.9) & 4965 (78.4) & $14,424(54.4)$ \\
\hline Tiotropium & $4516(22.3)$ & $3258(51.5)$ & $7774(29.3)$ \\
\hline Formoterol (mono-inhaler) & $383(1.9)$ & $221(3.5)$ & $604(2.3)$ \\
\hline LABA $^{\mathrm{b}}+$ ICS combination inhaler & NA & $5901(93.2)$ & $5901(22.2)$ \\
\hline \multicolumn{4}{|l|}{ Comorbidities, No. (\%) } \\
\hline Arrhythmia & $4824(23.9)$ & $1429(22.6)$ & $6253(23.6)$ \\
\hline Congestive heart failure & $2825(14.0)$ & $889(14.0)$ & $3714(14.0)$ \\
\hline Valvular heart disease & $1008(5.0)$ & $287(4.5)$ & $1295(4.9)$ \\
\hline Hypertension & $12,170(60.2)$ & $3923(62.0)$ & $16,093(60.6)$ \\
\hline Diabetes & $5345(26.4)$ & $1667(26.3)$ & $7012(26.4)$ \\
\hline Anemia & $157(0.8)$ & $46(0.7)$ & $203(0.8)$ \\
\hline Iron deficiency anemia & $1062(5.3)$ & $306(4.8)$ & $1368(5.2)$ \\
\hline Depression & $4438(22.0)$ & $1360(21.5)$ & $5798(21.8)$ \\
\hline Drug abuse & $1015(5.0)$ & $317(5.0)$ & $1332(5.0)$ \\
\hline Alcohol abuse & $2000(9.9)$ & $614(9.7)$ & $2614(9.9)$ \\
\hline Obesity $\left(\mathrm{BMI} \mathrm{c}^{\mathrm{c}} \geq 30 \mathrm{~kg} / \mathrm{m}^{2}\right)$ & $9961(49.3)$ & 3079 (48.6) & $13,040(49.1)$ \\
\hline \multicolumn{4}{|l|}{ Primary care clinic characteristics } \\
\hline \multicolumn{4}{|l|}{ Primary care site, No. $(\%)$} \\
\hline Medical center & $8006(39.6)$ & $2428(38.4)$ & $10,434(39.3)$ \\
\hline Community clinic & $12,200(60.4)$ & 3902 (61.6) & $16,102(60.7)$ \\
\hline \multicolumn{4}{|l|}{ Provider type, No. $(\%)$} \\
\hline Physician & $16,183(80.1)$ & $5093(80.5)$ & $21,276(80.2)$ \\
\hline Advanced practice provider & $4023(19.9)$ & $1237(19.5)$ & $5260(19.8)$ \\
\hline
\end{tabular}

${ }^{a}$ Primary care provider. ${ }^{b}$ Long-acting beta-agonist. ${ }^{c}$ Body mass index

complexity (community-based outpatient clinic [CBOC] vs. medical center) were not associated with potentially inappropriate ICS. Our sensitivity analysis, excluding 5649 patients with an FEV1 $<50 \%$ predicted, found the proportion of patients with potentially inappropriate ICS use was $19.7 \%$ ( $n$ = 4115). Age (APR 1.09 per 10 years, 1.06-1.12), distance $>$ 20 miles from PCP (APR 1.11, 1.05-1.18), cardiac arrhythmia (APR 0.93, 0.87-0.997), and frequency of primary care appointments (APR 1.06 per appt, 1.04-1.08) remained associated with potentially inappropriate ICS use.

\section{Potential Overuse and Misuse of ICS}

Among patients with airflow obstruction, 4922 (29.5\%) patients received ICS (potential overuse; Table 3). Among patients without airflow obstruction, 1408 (14.3\%) received ICS (potential misuse). To evaluate factors associated with potential overuse and misuse, we applied a similar modelling approach to each of these subgroups. We found that more frequent primary care visits increased the likelihood of ICS receipt among patients in both subgroups (Table 3). White race (APR 1.08, 95\% CI 1.01-1.15) and cardiac arrhythmia (APR 0.93, 95\% CI 0.88-0.99) remained associated with potential overuse of ICS. Age (APR 1.12 per decade, 95\% CI 1.07-1.17), drug abuse (APR 1.38, 95\% CI 1.16-1.64), and obesity (APR 1.31, 95\% CI 1.19-1.45) were associated with increased likelihood of potential misuse of ICS (Table 3). Although we found association in the overall cohort, distance from PCP was not associated independently with either potential misuse or potential overuse.

\section{DISCUSSION}

We found that approximately one in four patients with a clinical diagnosis of COPD, who lacked an indication for ICS based on current recommendations, received ICS during the study period. Prescriptions for ICS were common among patients without history of frequent or severe exacerbations (potential overuse) and among those who did not have airflow obstruction (potential misuse). Collectively, the degree of potentially inappropriate ICS prescriptions is consistent with 


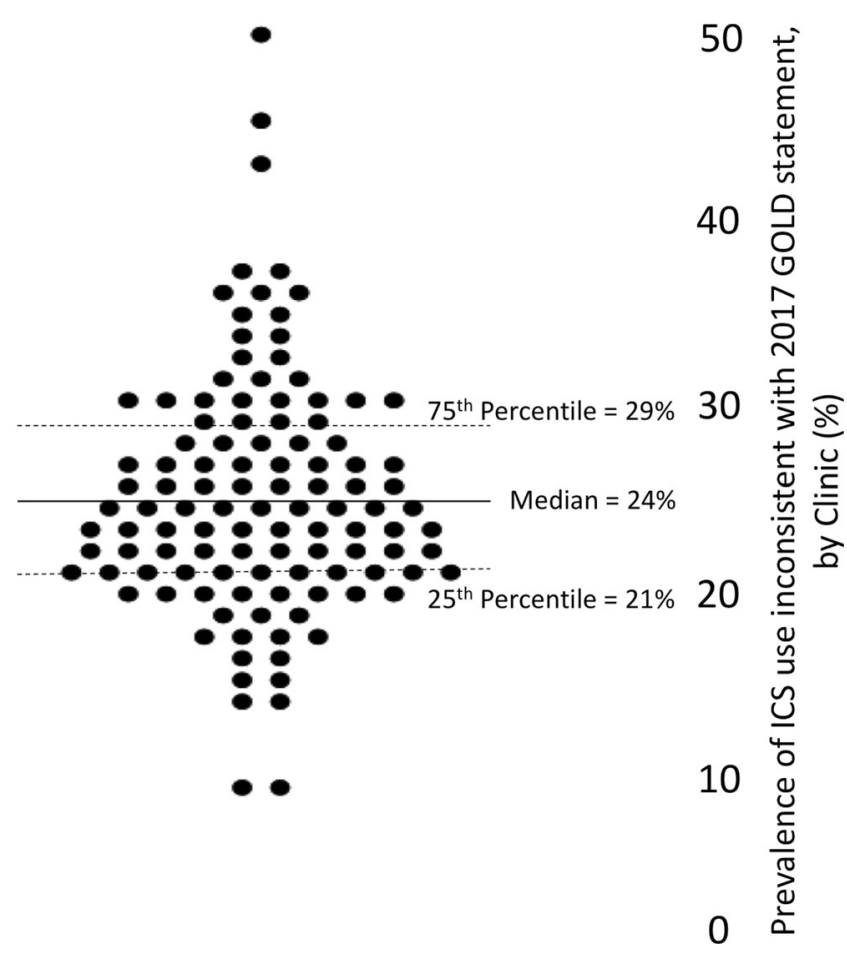

Figure 2 Proportion of patients with COPD receiving inhaled corticosteroid (ICS) prescriptions without an appropriate indication, ${ }^{14}$ by clinic. Appropriate indications for ICS use included asthma and history of frequent or severe exacerbations. ${ }^{14}$

the overall literature that demonstrates relatively poor quality of care for patients with COPD. ${ }^{16,18,29,30}$ Additionally, we identified particular patient characteristics associated with overuse and misuse that could be used to focus efforts to prevent low-value prescribing.

Our findings indicate that there are patient characteristics associated with an increased likelihood of inappropriate ICS use, regardless of GOLD statement used to determine appropriateness of ICS, many of which are also associated with receipt of other forms of low-value care. For example, we found that the distance that an individual must travel to his or her primary care clinic increased the likelihood of receiving potentially inappropriate ICS prescriptions. This finding is in line with prior findings that overall healthcare utilization increases with distance among patients in health systems similar to the VA. ${ }^{31}$ There are several potential heuristics that could account for these findings, including that patients who live further away may express greater desire to maximize therapy or providers may be more likely to attempt empirical treatment of symptoms for convenience. Frequent attendance in primary care clinic increased the likelihood of receiving potentially inappropriate ICS prescriptions and has been shown to increase the likelihood of receiving other forms of low-value care. ${ }^{32}$ This finding may indicate that providers are more likely to escalate treatment for individuals with persistent symptoms that appear out of proportion to objective findings of disease severity. Alternatively, increased prescriptions could result from greater opportunity to receive ICS with each visit. Consistent with our findings, white race has been associated with increased likelihood of receiving other inappropriate services and therapies and may represent an unintended effect of imbalances in the social determinants of health. ${ }^{33-35}$

Table 2 - Patient and provider characteristics associated with potentially inappropriate inhaled corticosteroid (ICS) use among patients with COPD. Appropriate indications for ICS use included asthma and history of frequent or severe exacerbations.

\begin{tabular}{|c|c|c|}
\hline & Unadjusted Prevalence Ratio & Adjusted Prevalence Ratio \\
\hline Using ICS without indication, No (\%) & $6,330(23.9)$ & \\
\hline \multicolumn{3}{|l|}{ Patient Characteristics } \\
\hline Gender - Male, PR ${ }^{\mathrm{a}}\left(95 \% \mathrm{CI}^{\mathrm{b}}\right)$ & $1.22(1.02-1.48)^{\mathrm{e}}$ & $1.17(0.97-1.41)$ \\
\hline Age, per decade PR $(95 \% \mathrm{CI})$ & $1.05(1.03-1.07)^{\mathrm{f}}$ & $1.06(1.04-1.08)^{\mathrm{f}}$ \\
\hline \multicolumn{3}{|l|}{ Race, PR $(95 \% \mathrm{CI})$} \\
\hline White & $1.13(1.06-1.20)^{\mathrm{f}}$ & $1.11(1.05-1.19)^{\mathrm{e}}$ \\
\hline Non-White & Ref & Ref \\
\hline $\mathrm{PCP}^{\mathrm{C}}$ appointments in last year (per appointment), $\mathrm{PR}(95 \% \mathrm{CI})$ & $1.04(1.03-1.05)^{\mathrm{f}}$ & $1.05(1.03-1.07)^{\mathrm{f}}$ \\
\hline Non-COPD related hospitalizations in last year (per hospitalization), PR (95\%CI) & $0.97(0.93-1.02)$ & $0.97(0.92-1.01)$ \\
\hline Living more than 20 miles from $\mathrm{PCP}^{\mathrm{c}} \mathrm{PR}(95 \% \mathrm{CI})$ & $1.05(1.00-1.11)^{\mathrm{e}}$ & $1.06(1.00-1.11)^{\mathrm{e}}$ \\
\hline \multicolumn{3}{|l|}{ Comorbidities, PR (95\% CI) } \\
\hline Arrhythmia & $0.95(0.91-0.998)^{\mathrm{e}}$ & $0.92(0.87-0.97)^{\mathrm{e}}$ \\
\hline Congestive Heart Failure (CHF) & $1.01(0.95-1.07)$ & $1.02(0.96-1.08)$ \\
\hline Valvular Heart Disease & $0.94(0.86-1.01)$ & $0.92(0.85-1.00)$ \\
\hline Anemia & $0.95(0.70-1.29)$ & $0.99(0.75-1.33)$ \\
\hline Iron Deficiency Anemia & $0.94(0.85-1.04)$ & $0.94(0.86-1.04)$ \\
\hline Depression & $0.97(0.92-1.02)$ & $0.97(0.92-1.02)$ \\
\hline Drug Abuse & $1.01(0.92-1.12)$ & $1.08(0.98-1.18)$ \\
\hline Alcohol Abuse & $1.00(0.93-1.08)$ & $1.03(0.95-1.11)$ \\
\hline Obesity $\left(\mathrm{BMI}{ }^{\mathrm{d}}>30 \mathrm{~kg} / \mathrm{m}^{2}\right)$ & $0.97(0.92-1.01)$ & $0.96(0.92-1.01)$ \\
\hline \multicolumn{3}{|l|}{ Primary Care Clinic Characteristics } \\
\hline \multicolumn{3}{|l|}{ Primary Care site, PR $(95 \% \mathrm{CI})$} \\
\hline Medical Center & Ref & Ref \\
\hline Community Clinic & $1.06(0.95-1.17)$ & $1.03(0.92-1.15)$ \\
\hline \multicolumn{3}{|l|}{ Provider Type, PR (95\%CI) } \\
\hline MD & Ref & Ref \\
\hline Advance Practice Provider & $1.05(0.99-1.11)$ & $1.05(0.99-1.11)$ \\
\hline
\end{tabular}

${ }^{a}$ Prevalence Ratio, ${ }^{b}$ Confidence Interval, ${ }^{c}$ Primary Care Provider, ${ }^{d}$ Body Mass Index, ${ }^{e} p<0.05,{ }_{p}<0.001$ 
Table 3 - Patient and provider characteristics associated with potentially inappropriate inhaled corticosteroid (ICS) use among patients with a clinical diagnosis of COPD, stratified by absence or presence of airflow obstruction (misuse and overuse, respectively) Appropriate indications for ICS use included asthma and history of frequent or severe exacerbations. ${ }^{1}$

\begin{tabular}{|c|c|c|c|c|}
\hline & \multicolumn{2}{|c|}{$\begin{array}{l}\text { Patients w/ Airflow Obstruction } \\
(\text { No. }=16,682)\end{array}$} & \multicolumn{2}{|c|}{$\begin{array}{l}\text { Patients w/o Airflow Obstruction } \\
(\text { No. }=9,854)\end{array}$} \\
\hline & Unadjusted $\mathbf{P R}^{\mathbf{a}}$ & Adjusted PR & Unadjusted PR & Adjusted PR \\
\hline Using ICS without indication, No (\%) & $4,922(29.5)$ & & $1,408(14.3)$ & \\
\hline \multicolumn{5}{|l|}{ Patient Characteristics } \\
\hline Gender - Male, $\mathrm{PR}^{\mathrm{a}}\left(95 \% \mathrm{CI}^{\mathrm{b}}\right)$ & $1.06(0.86-1.29)$ & $1.07(0.87-1.31)$ & $1.09(0.79-1.50)$ & $1.02(0.75-1.43)$ \\
\hline Age, per decade PR $(95 \% \mathrm{CI})$ & $0.98(0.96-1.01)$ & $0.98(0.95-1.00)$ & $1.08(1.03-1.13)^{\mathrm{f}}$ & $1.12(1.07-1.17)^{\mathrm{f}}$ \\
\hline \multicolumn{5}{|l|}{ Race, PR $(95 \%$ CI $)$} \\
\hline White & $1.09(1.01-1.16)^{\mathrm{e}}$ & $1.08(1.01-1.15)^{\mathrm{e}}$ & $1.00(0.86-1.16)$ & $0.97(0.83-1.13)$ \\
\hline Non-White & Ref & Ref & Ref & Ref \\
\hline $\mathrm{PCP}^{\mathrm{C}}$ appointments in last year (per appointment), $\mathrm{PR}$ (95\%CI) & $1.05(1.03-1.07)^{\mathrm{f}}$ & $1.05(1.03-1.07)^{\mathrm{f}}$ & $1.07(1.05-1.09)^{\mathrm{f}}$ & $1.07(1.04-1.09)^{\mathrm{f}}$ \\
\hline Non-COPD related hospitalizations in last year (per & $0.99(0.96-1.02)$ & $0.98(0.95-1.02)$ & $0.99(0.92-1.06)$ & $0.96(0.90-1.04)$ \\
\hline \multicolumn{5}{|l|}{ hospitalization), PR (95\% CI) } \\
\hline Living more than 20 miles from $\mathrm{PCP}^{\mathrm{c}} \mathrm{PR}(95 \% \mathrm{CI})$ & $1.05(0.99-1.11)$ & $1.05(0.99-1.11)$ & $1.09(0.96-1.24)$ & $1.10(0.96-1.27)$ \\
\hline \multicolumn{5}{|l|}{ Comorbidities, PR (95\%CI) } \\
\hline Arrhythmia & $0.96(0.92-1.02)$ & $0.93(0.88-0.99)^{\mathrm{e}}$ & $1.00(0.91-1.11)$ & $0.91(0.81-1.03)$ \\
\hline Congestive Heart Failure (CHF) & $1.04(0.96-1.12)$ & $1.05(0.97-1.13)$ & $1.04(0.95-1.15)$ & $0.98(0.87-1.10)$ \\
\hline Valvular Heart Disease & $0.95(0.87-1.05)$ & $0.95(0.86-1.04)$ & $1.00(0.82-1.22)$ & $0.96(0.78-1.18)$ \\
\hline Anemia & $0.92(0.65-1.29)$ & $0.93(0.66-1.30)$ & $1.13(0.73-1.75)$ & $1.16(0.77-1.76)$ \\
\hline Iron Deficiency Anemia & $0.96(0.86-1.07)$ & $0.95(0.86-1.06)$ & $1.00(0.81-1.24)$ & $0.97(0.77-1.21)$ \\
\hline Depression & $1.01(0.95-1.08)$ & $0.99(0.93-1.05)$ & $1.10(0.97-1.25)$ & $1.08(0.96-1.21)$ \\
\hline Drug Abuse & $0.96(0.86-1.07)$ & $0.97(0.88-1.09)$ & $1.30(1.10-1.53)^{\mathrm{e}}$ & $1.38(1.16-1.64)^{\mathrm{f}}$ \\
\hline Alcohol Abuse & $0.97(0.90-1.05)$ & $0.97(0.90-1.05)$ & $1.08(0.93-1.26)$ & $1.09(0.93-1.27)$ \\
\hline Obesity $\left(\mathrm{BMI}^{\mathrm{d}}>30 \mathrm{~kg} / \mathrm{m}^{2}\right)$ & $1.03(0.97-1.08)$ & $1.01(0.96-1.06)$ & $1.30(1.18-1.44)^{\mathrm{f}}$ & $1.31(1.19-1.45)^{\mathrm{f}}$ \\
\hline \multicolumn{5}{|l|}{ Primary Care Clinic Characteristics } \\
\hline \multicolumn{5}{|l|}{ Primary Care site, PR $(95 \% \mathrm{CI})$} \\
\hline Medical Center & Ref & Ref & Ref & Ref \\
\hline Community Clinic & $1.05(0.95-1.17)$ & $1.04(0.92-1.16)$ & $1.06(0.87-1.29)$ & $1.04(0.85-1.28)$ \\
\hline \multicolumn{5}{|l|}{ Provider Type, PR (95\%CI) } \\
\hline MD & Ref & Ref & Ref & Ref \\
\hline Advance Practice Provider & $1.03(0.98-1.09)$ & $1.04(0.99-1.11)$ & $1.07(0.94-1.23)$ & $1.07(0.94-1.23)$ \\
\hline
\end{tabular}

${ }^{a}$ Prevalence Ratio, ${ }^{b}$ Confidence Interval, ${ }^{c}$ Primary Care Provider, ${ }^{d}$ Body Mass Index, ${ }^{e} p<0.05,{ }_{p<0.001}$

${ }^{I}$ From the Global Strategy for the Diagnosis M, and Prevention of COPD,. Global Initiative for Chronic Lung Disease (GOLD). 2017; http://goldcopd. org.

Given the large variation in practice we found between clinics, further work is needed to understand the successful processes in place at high-performing sites that limit potentially inappropriate ICS prescriptions as these may shed light on opportunities to overcome disparities in care delivery, such as race and rural residence.

A high proportion of patients with potentially inappropriate ICS use were prescribed LABA/ICS combination inhalers $(93.2 \%)$ and not single-drug ICS inhalers $(6.8 \%)$. There are many potential explanations for the high proportion of combination inhaler use including the following: updated GOLD recommendations in 2011 which discouraged ICS monotherapy, fears about the dangers of LABA monotherapy among patients with asthma (LABA monotherapy is not associated with increased mortality in COPD), and increased awareness of combination inhaler formulations due to extensive directto-consumer marketing. ${ }^{13,}{ }^{36-38}$ However, it is also possible that physicians prescribed combination inhalers in place of single-drug inhalers out of fear they could be perceived as not doing enough. When making prescribing decisions, providers often let emotional triggers, including the fear of being perceived as doing "nothing," drive treatment decisions in place of an evaluation of potential adverse effects. ${ }^{39}$ The importance of emotion in this prescribing decision is supported by our finding that patients who see their provider more often are more likely to receive an ICS. Qualitative research is needed to better understand the drivers of inappropriate ICS use, similar to work done regarding inappropriate antibiotic prescribing, to inform effective de-implementation efforts. ${ }^{39}$

Creating structures and processes to support deimplementation of ICS among COPD patients without an appropriate indication should take behavioral economics into account, acknowledging that discontinuation of ICS and limiting the ability to prescribe ICS may result in a sense of loss to patients and providers. ${ }^{40,41}$ Although taking away a service is perceived more negatively than never starting that service, some have suggested that substituting alternate therapies may mitigate this sense of loss. ${ }^{42}$ For example, in the context of overuse, replacing ICS with a long-acting inhaled bronchodilator or pulmonary rehabilitation may improve symptoms and reduce any sense of loss. ${ }^{42}$ Among patients without airflow obstruction, efforts on weight loss for obese patients or addiction counseling for those with substance abuse issues may substitute for potentially unnecessary ICS prescriptions.

Our results also suggest that interventions may need to provide guidance on etiologies of common respiratory symptoms as nearly half of the patients in our cohort did not have airflow obstruction despite a clinical diagnosis of COPD. 
Previous work has demonstrated that many patients with clinical diagnoses of COPD lack airflow obstruction and that primary care providers are unlikely to change management even in the context of normal spirometry. ${ }^{17,22,43-47}$ Given these perspectives, health systems may need to design interventions that facilitate implementation of high-value, evidence-based care across diverse clinical sites and support primary care clinicians to adopt guideline standards. ${ }^{48}$

This study had some potential limitations. First, our population consisted entirely of Veterans, a population of predominantly white men with lower socioeconomic means. Second, we assumed that patients who filled medications used medications. We chose two patient-initiated dispensations as our outcome. The VA typically provides 3-month allocations of medication per dispensation, suggesting that patients were exposed to at least a 6-month supply of medications. Independent of whether patients used these medications, dispensations result in costs to patients and the healthcare system due to costs of drug acquisition and supply. Third, we were not able to assess whether patients received ICS prescriptions from outside the VA; thus, our estimate of ICS use is conservative. Finally, available spirometry data was limited to select facilities that voluntarily uploaded their results to the CDW. We may not be able to generalize these findings across the entire VA system; however, the facilities included in our study represented all four US Census Bureau regions and seven of the nine US Census Bureau divisions, suggesting adequate regional diversity. ${ }^{49}$

This study also had several strengths. First, we used spirometry to confirm the presence or absence of airflow obstruction for all patients, which is rarely available in most clinically derived, observational studies. This information allowed us to capture the magnitude of misdiagnosis among patients targeted for de-implementation of ICS. ${ }^{29,50,51}$ Second, our use of the CDW allowed for a comprehensive view of actual healthcare delivery. For example, linking pharmacy information regarding the dispensation of oral steroids and respiratory antibiotics to clinical encounters for COPD allowed us to more accurately identify outpatient exacerbations than relying entirely on ICD coding for that encounter. Third, the geographic diversity of our clinical sites limited the possibility that any given regional practice accounted for our findings. Last, we were able to incorporate provider, clinic, and patient factors into this analysis.

De-implementation of low-value practices that are known to be ineffective or harmful provides a new area of opportunity to improve healthcare quality. As we have learned with implementation of beneficial healthcare practices, change often fails because inadequate research has taken place prior to implementation. With this project, we set out to identify the particular characteristics of patients with COPD who are more likely to receive inappropriate ICS, in order to understand the patient and provider factors that drive this particular form of low-value care. These findings could inform the development of local or systemic processes to counter the observed patterns of inappropriate ICS prescribing, as the initial step in an ongoing quality improvement process focused on de-implementation. De-implementation is a necessary step in the evolution of healthcare quality to bring us closer to the triple aim of safe, patient-centered, and cost-effective care. ${ }^{52}$

Acknowledgments: We would like to acknowledge Robert Plumley for his efforts in data acquisition and analysis.

Corresponding Author: Matthew F. Griffith, MD, MPH; Division of Pulmonary, Critical Care and Sleep MedicineUniversity of Washington, Seattle, WA, USA (e-mail: Matthew.griffith@va.gov).

Funding Information NIH NHLBI K23 HL111116, NIH NHLBI T32 HL007287, NIH NHLBI K12HL137940, VA QUERI IO1 HXOO2113

\section{Compliance with Ethical Standards:}

Conflict of Interest: The authors declare that they do not have a conflict of interest.

\section{REFERENCES}

1. Calverley PM, Anderson JA, Celli B, et al. Salmeterol and fluticasone propionate and survival in chronic obstructive pulmonary disease. N Engl J Med. 2007;356(8):775-789.

2. Chapman KR, Rennard SI, Dogra A, et al. Long-term safety and efficacy of indacaterol, a long-acting beta(2)-agonist, in subjects with COPD: a randomized, placebo-controlled study. Chest. 2011;140(1):68-75.

3. Koch A, Pizzichini E, Hamilton A, et al. Lung function efficacy and symptomatic benefit of olodaterol once daily delivered via Respimat(R) versus placebo and formoterol twice daily in patients with GOLD 2-4 COPD: results from two replicate 48-week studies. Int $\mathrm{J}$ Chron Obstruct Pulmon Dis. 2014;9:697-714.

4. Casaburi R, Mahler DA, Jones PW, et al. A long-term evaluation of oncedaily inhaled tiotropium in chronic obstructive pulmonary disease. Eur Respir J. 2002;19(2):217-224.

5. Vincken W, van Noord JA, Greefhorst AP, et al. Improved health outcomes in patients with COPD during 1 yr's treatment with tiotropium. Eur Respir J. 2002; 19(2):209-216

6. Dusser D, Bravo ML, Iacono P. The effect of tiotropium on exacerbations and airflow in patients with COPD. Eur Respir J. 2006;27(3):547-555.

7. Niewoehner DE, Rice $\mathbf{K}$, Cote $\mathbf{C}$, et al. Prevention of exacerbations of chronic obstructive pulmonary disease with tiotropium, a once-daily inhaled anticholinergic bronchodilator: a randomized trial. Ann Intern Med. 2005;143(5):317-326.

8. Wedzicha JA, Calverley PM, Seemungal TA, et al. The prevention of chronic obstructive pulmonary disease exacerbations by salmeterol/ fluticasone propionate or tiotropium bromide. Am J Respir Crit Care Med. 2008;177(1):19-26.

9. NICE NIfHaCE. Chronic Obstructive Pulmonary Disease in over 16s: diagnosis and management. 2010

10. Ernst P, Gonzalez AV, Brassard P, Suissa S. Inhaled corticosteroid use in chronic obstructive pulmonary disease and the risk of hospitalization for pneumonia. Am J Respir Crit Care Med. 2007;176(2):162-166.

11. Suissa S, Patenaude V, Lapi F, Ernst P. Inhaled corticosteroids in COPD and the risk of serious pneumonia. Thorax. 2013;68(11):1029-1036.

12. Suissa S, Coulombe J, Ernst P. Discontinuation of Inhaled Corticosteroids in COPD and the Risk Reduction of Pneumonia. Chest. 2015;148(5):1177-1183.

13. Vestbo J, Hurd SS, Rodriguez-Roisin R. The 2011 revision of the global strategy for the diagnosis, management and prevention of COPD (GOLD)why and what? Clin Respir J. 2012;6(4):208-214.

14. From the Global Strategy for the Diagnosis M, and Prevention of COPD,. Global Initiative for Chronic Lung Disease (GOLD). 2017; http:// goldcopd.org. (Accessed August 28, 2019).

15. Franssen FM, Spruit MA, Wouters EF. Determinants of polypharmacy and compliance with GOLD guidelines in patients with chronic obstructive pulmonary disease. Int $\mathrm{J}$ Chron Obstruct Pulmon Dis. 2011;6:493501. 
16. White $\mathbf{P}$, Thornton H, Pinnock H, Georgopoulou S, Booth HP. Overtreatment of COPD with inhaled corticosteroids-implications for safety and costs: cross-sectional observational study. PLoS One. 2013;8(10):e75221.

17. Collins BF, Feemster LC, Rinne ST, Au DH. Factors predictive of airflow obstruction among veterans with presumed empirical diagnosis and treatment of COPD. Chest. 2015;147(2):369-376.

18. Falk J, Dik N, Bugden S. An evaluation of early medication use for COPD: a population-based cohort study. Int $\mathrm{J}$ Chron Obstruct Pulmon Dis. 2016;11:3101-3108.

19. Zhang Y, Baicker K, Newhouse JP. Geographic variation in the quality of prescribing. N Engl J Med. 2010;363(21):1985-1988.

20. Global Initiative for Chronic Obstructie Lung Disease (GOLD). Spirometry for Healthcare Providers. 2010; http://goldcopd.org/wp-content/uploads/2016/04/GOLD_Spirometry_2010.pdf. (Accessed August 28, 2019).

21. The Overuse, Underuse, and Misuse of Health Care. Senate Committee on Finance, 2nd edn. 2008.

22. Collins BF, Ramenofsky D, Au DH, Ma J, Uman JE, Feemster LC. The association of weight with the detection of airflow obstruction and inhaled treatment among patients with a clinical diagnosis of COPD. Chest. 2014;146(6): 1513-1520.

23. Cecere LM, Littman AJ, Slatore CG, et al. Obesity and COPD: associated symptoms, health-related quality of life, and medication use. COPD. 2011;8(4):275-284

24. Elixhauser A, Steiner C, Harris DR, Coffey RM. Comorbidity measures for use with administrative data. Med Care. 1998;36(1):8-27.

25. Yen W. How Long and Far Do Adults and Will Adults Travel for Primary Care. https://ofm.wa.gov/sites/default/files/public/legacy/ researchbriefs/2013/brief070.pdf: Office of Financial Management; April 2013. (Accessed August 28, 2019)

26. Barros AJ, Hirakata VN. Alternatives for logistic regression in crosssectional studies: an empirical comparison of models that directly estimate the prevalence ratio. BMC Med Res Methodol. 2003;3:21.

27. Hedeker D, Gibbons RD, Flay BR. Random-effects regression models for clustered data with an example from smoking prevention research. J Consult Clin Psychol. 1994;62(4):757-765.

28. Orszag PR. Increasing the Value of Federal Spending on Health Care. Washington, DC: Congressional Budget Office; 2008.

29. Lee TA, Bartle B, Weiss KB. Spirometry use in clinical practice following diagnosis of COPD. Chest. 2006;129(6):1509-1515.

30. Arne $\mathbf{M}$, Lisspers $\mathbf{K}$, Stallberg $\mathbf{B}$, et al. How often is diagnosis of COPD confirmed with spirometry? Respir Med. 2010;104(4):550-556.

31. Billi JE, Pai CW, Spahlinger DA. The effect of distance to primary care physician on health care utilization and disease burden. Health Care Manag Rev. 2007;32(1):22-29.

32. Reid S, Wessely S, Crayford T, Hotopf M. Frequent attenders with medically unexplained symptoms: service use and costs in secondary care. Br J Psychiatry. 2002; 180:248-253.

33. Foy R, Leaman B, McCrorie $\mathbf{C}$, et al. Prescribed opioids in primary care: cross-sectional and longitudinal analyses of influence of patient and practice characteristics. BMJ Open. 2016;6(5):e010276.

34. Calderon-Larranaga A, Poblador-Plou B, Gonzalez-Rubio F, GimenoFeliu LA, Abad-Diez JM, Prados-Torres A. Multimorbidity, polypharmacy, referrals, and adverse drug events: are we doing things well? Br J Gen Pract. 2012;62(605):e821-826.

35. Kroll DS, Nieva HR, Barsky AJ, Linder JA. Benzodiazepines are Prescribed More Frequently to Patients Already at Risk for Benzodiazepine-Related Adverse Events in Primary Care. J Gen Intern Med. 2016;31(9): 1027-1034.
36. Daubresse M, Hutfless S, Kim Y, et al. Effect of Direct-to-Consumer Advertising on Asthma Medication Sales and Healthcare Use. Am J Respir Crit Care Med. 2015; 192(1):40-46.

37. Wijesinghe $\mathbf{M}$, Perrin $\mathbf{K}$, Harwood $\mathbf{M}$, Weatherall $\mathbf{M}$, Beasley $\mathbf{R}$. The risk of asthma mortality with inhaled long acting beta-agonists. Postgrad Med J. 2008;84(995):467-472

38. Rodrigo GJ, Nannini LJ, Rodriguez-Roisin R. Safety of long-acting beta-agonists in stable COPD: a systematic review. Chest. 2008; 133(5): 1079-1087.

39. Livorsi D, Comer A, Matthias MS, Perencevich EN, Bair MJ. Factors Influencing Antibiotic-Prescribing Decisions Among Inpatient Physicians: A Qualitative Investigation. Infect Control Hosp Epidemiol. 2015;36(9): 1065-1072.

40. Reeve E, To J, Hendrix I, Shakib S, Roberts MS, Wiese MD. Patient barriers to and enablers of deprescribing: a systematic review. Drugs Aging. 2013;30(10):793-807.

41. Schuling J, Gebben H, Veehof LJ, Haaijer-Ruskamp FM. Deprescribing medication in very elderly patients with multimorbidity: the view of Dutch GPs. A qualitative study. BMC Fam Pract. 2012;13:56.

42. Helfrich CD, Rose AJ, Hartmann CW, et al. How the dual process model of human cognition can inform efforts to de-implement ineffective and harmful clinical practices: A preliminary model of unlearning and substitution. J Eval Clin Pract. 2018;24(1):198-205.

43. Yawn BP, Enright PL, Lemanske RF, Jr., et al. Spirometry can be done in family physicians' offices and alters clinical decisions in management of asthma and COPD. Chest. 2007;132(4):1162-1168.

44. Rutschmann OT, Janssens JP, Vermeulen B, Sarasin FP. Knowledge of guidelines for the management of COPD: a survey of primary care physicians. Respir Med. 2004;98(10):932-937.

45. Davis KJ, Landis SH, Oh YM, et al. Continuing to Confront COPD International Physician Survey: physician knowledge and application of COPD management guidelines in 12 countries. Int $\mathrm{J}$ Chron Obstruct Pulmon Dis. 2015;10:39-55.

46. Hernandez P, Balter MS, Bourbeau J, Chan CK, Marciniuk DD, Walker SL. Canadian practice assessment in chronic obstructive pulmonary disease: respiratory specialist physician perception versus patient reality. Can Respir J. 2013;20(2):97-105.

47. Joo MJ, Sharp LK, Au DH, Lee TA, Fitzgibbon ML. Use of spirometry in the diagnosis of COPD: a qualitative study in primary care. COPD. 2013; 10(4):444-449.

48. Cabana MD, Rand CS, Powe NR, et al. Why don't physicians follow clinical practice guidelines? A framework for improvement. JAMA. 1999;282(15):1458-1465

49. US Census Bureau. Geographic Terms and Concepts - Census Divisions and Census Regions. https://www2.census.gov/geo/pdfs/maps-data/ maps/reference/us_regdiv.pdf. Accessed August 28, 2019.

50. Han MK, Kim MG, Mardon R, et al. Spirometry utilization for COPD: how do we measure up? Chest. 2007;132(2):403-409.

51. Joo MJ, Lee TA, Weiss KB. Geographic variation of spirometry use in newly diagnosed COPD. Chest. 2008;134(1):38-45

52. Berwick DM, Nolan TW, Whittington J. The triple aim: care, health, and cost. Health Aff (Millwood). 2008;27(3):759-769.

Publisher's Note: Springer Nature remains neutral with regard to jurisdictional claims in published maps and institutional affiliations. 